\title{
Resultados del primer año de funcionamiento del plan de resucitación cardiopulmonar del Hospital Juan Ramón Jiménez (Huelva)
}

\author{
M. Herrera ${ }^{a, *}$, F. López ${ }^{b}$, H. González ${ }^{a}$, P. Domínguez ${ }^{a}$, C. García ${ }^{c}$ y C. Bocanegra ${ }^{d}$ \\ aUnidad de Cuidados Intensivos, Servicio de Cuidados Críticos y Urgencias, Hospital Juan Ramón Jiménez, Huelva, España \\ ${ }^{\mathrm{b}}$ Bloque de Enfermería de Cuidados Críticos y Urgencias, Hospital Juan Ramón Jiménez, Huelva, España \\ 'Formación Continuada de Enfermería, Hospital Juan Ramón Jiménez, Huelva, España \\ ${ }^{d}$ Servicio de Farmacia Hospitalaria, Hospital Juan Ramón Jiménez, Huelva, España
}

Recibido el 25 de julio de 2009; aceptado el 10 de noviembre de 2009

Disponible en Internet el 21 de enero de 2010

\author{
PALABRAS CLAVE \\ Parada cardíaca \\ hospitalaria; \\ Resucitación \\ cardiopulmonar; \\ Plan hospitalario de \\ resucitación \\ cardiopulmonar; \\ Estilo Utstein
}

\begin{abstract}
Resumen
Objetivo: Presentar los resultados del primer año de funcionamiento de un plan hospitalario de resucitación cardiopulmonar (RCP) y describir las características de los pacientes con parada cardiorrespiratoria (PCR) en unidades de hospitalización (UH) no monitorizadas.

Diseño: Estudio observacional prospectivo de una cohorte de pacientes que han presentado PCR durante un período de un año.

Ámbito: La UH de un hospital general y de referencia provincial.

Pacientes y métodos: Pacientes ingresados en la UH desde mayo de 2007 hasta mayo de 2008 con PCR y asistidos según un plan de RCP propio del hospital, organizado sobre la base de: a) descentralizar la RCP mediante la formación de la enfermera como primer interviniente capaz de realizar una RCP inmediata y una desfibrilación (DF) temprana (menos de $4 \mathrm{~min}$ ); b) un teléfono específico de alarma hospitalaria de PCR, y c) la continuación de las maniobras de RCP por un equipo de soporte vital avanzado (ESVA) de intervención precoz (menos de $8 \mathrm{~min}$ ).

Variables de interés principales: Características del paciente, episodio de PCR y resultados según el estilo "Utstein".

Resultados: Se incluyó a 73 pacientes con activación de la alarma de PCR, 8 de ellas falsas, con edad media de 70 años y el $60 \%$ hombres. El $65 \%$ se produjo en áreas médicas en pacientes con insuficiencia cardíaca, respiratoria, sepsis o shock séptico. El ritmo cardíaco inicial de los enfermos atendidos fue asistolia en el $74 \%$, fibrilación ventricular en el $18 \%$ y disociación electromecánica en el $8 \%$. El primer interviniente fue la enfermera en el $79 \%$ de los casos, la RCP se inició siempre en menos de $1 \mathrm{~min}$, la DF en menos de 2 min en el $92 \%$
\end{abstract}

\footnotetext{
*Autor para correspondencia.

Correo electrónico: maheca@ono.com (M. Herrera).
} 


\section{KEYWORDS}

In-hospital cardiac

arrest;

Cardiopulmonary

resuscitation;

Cardiopulmonary

resuscitation hospital

plan;

Utstein style y el ESVA en menos de 8 min en el $96 \%$. Un 55\% de los enfermos atendidos sobrevivió y a un $38 \%$ se les dio de alta del hospital vivos (el 78\% con buena evolución neurológica).

Conclusiones: El plan de RCP del Hospital Juan Ramón Jiménez es una iniciativa aplicable y efectiva en nuestro entorno.

(c) 2009 Elsevier España, S.L. y SEMICYUC. Todos los derechos reservados.

Results of the first year of experience of the cardiopulmonary resuscitation program “Juan Ramón Jiménez" Hospital (Huelva)

\begin{abstract}
Objective: To present the results of the first year of the functioning of a Cardiopulmonary Resuscitation (CPR) Hospital Plan and to describe the characteristics of the patients with cardiopulmonary arrest (CPA) in hospital units with no monitoring facilities (HU).

Design: An observational, prospective study in a cohort of patients who presented CPA during a one-year period.

Setting: HU of a general hospital and as province reference.

Patients and methods: Patients admitted to an HU from May 2007 to May 2008 with CPA and treated according to a specific hospital CPA Program, organized in order to: (a) decentralize the CPR through the training of the nurse as the first responder capable of performing immediate CPR and early defibrillation (DF) (less than $4 \mathrm{~min}$ ), (b) a specific phone number as hospital alarm of CPR and (c) maintenance of the CPR maneuvers by an early intervention Resuscitation Team (RT) (less than $8 \mathrm{~min}$ ).

Main variables of interest: Characteristics of patients, CPA episode and results according to the «Utstein style».

Results: A total of 73 patients were included with activation of the CPA alarm, 8 of which were false alarms, with an average age of 70 years and $60 \%$ men. A total of $65 \%$ occurred in the medical area in patients with heart or respiratory failure, sepsis or septic shock. Initial heart rhythm of the patients attended was asystolic in $74 \%$ of the patients, ventricular fibrillation in $18 \%$ and electromechanical dissociation in $8 \%$. The first attending person was the nurse in $79 \%$ of cases, CPR was always initiated in less than $1 \mathrm{~min}$, DF in less than $2 \mathrm{~min}$ (92\%) and RT in less than $8 \mathrm{~min}(96 \%)$. Fifty-five percent survived and $35 \%$ of the reanimated patients were discharged live from the hospital, $78 \%$ with good neurological outcomes.

Conclusions: The CPR "Juan Ramón Jiménez" Hospital Program is an applicable and effective initiative in our setting.

(c) 2009 Elsevier España, S.L. and SEMICYUC. All rights reserved.
\end{abstract}

\section{Introducción}

Las muertes por parada cardiorrespiratoria (PCR) son un problema de gran envergadura para la salud pública con un gran impacto social, sanitario y económico. Se calcula que en España cada año son susceptibles de resucitación cardiopulmonar (RCP) más de 24.500 personas en la comunidad, lo que corresponde a una media de un paro cardíaco cada 20 min, y origina 4 veces más muertes que los accidentes de tráfico ${ }^{1,2}$. En el medio hospitalario se desconoce esta cifra porque nuestro país carece de registros hospitalarios de PCR y, por consiguiente, de datos fidedignos. Se estima que la cifra de pacientes que se tratan anualmente de una PCR intrahospitalaria en Estados Unidos es de 370.000 a 750.000 y en Europa de 700.000. La literatura médica internacional considera que entre el 0,4 y el $2 \%$ de los pacientes ingresados y hasta el $30 \%$ de los fallecidos precisa de $\mathrm{RCP}^{3-6}$, lo que supondría por extrapolación unos 18.000 afectados en España ${ }^{7}$.

La supervivencia de los pacientes con PCR hospitalarias es baja, pues en las mejores series la mortalidad es del $80-85 \%$ y sólo uno de cada 6 pacientes tratados sobrevivirá y se dará de alta ${ }^{8-11}$. En una revisión de 25 estudios efectuados entre
1959 y 1992 se constató una tasa de supervivencia hospitalaria del $11,2 \%$, aunque los resultados pueden variar mucho en función de que el episodio ocurra en áreas de críticos (unidad de cuidados intensivos [UCI], urgencias, quirófano y reanimación) o en unidades de hospitalización (UH) no monitorizadas ${ }^{12-14}$.

Sin embargo, existe la evidencia de que puede reducirse la mortalidad y las secuelas que causan las PCR en el hospital si se mejora la respuesta asistencial. Para ello, se propugna una estrategia basada en la optimización de la llamada “cadena de supervivencia hospitalaria", constituida por: 1) un sistema de alerta inmediata; 2) el inicio precoz de la RCP básica; 3) la desfibrilación (DF) temprana, y 4) el soporte vital avanzado en escasos minutos ${ }^{15,16}$. Evidentemente, hay que asegurar una rápida aplicación de medidas de RCP y DF, pero también la PCR hospitalaria refleja frecuentemente situaciones previas de importante deterioro fisiológico de los enfermos, por lo que en estudios recientes se ha puesto de manifiesto la necesidad de implementar también el primero y el cuarto de los eslabones, es decir, la detección de los pacientes en riesgo y la adopción de medidas de prevención del paro cardíaco y los cuidados posresucitación, respectivamente $^{17,18}$. En nuestro país son pocos los hospitales que 
tienen organizada de esta manera unificada y protocolizada la atención a los enfermos con PCR.

El objetivo del presente estudio es mostrar los resultados del primer año de experiencia de la implantación de un plan de RCP hospitalario, y analizar: 1) la operatividad de éste; 2) las características demográficas y clínicas de los enfermos en los que se activó la alerta de PCR; 3) la supervivencia inmediata, la supervivencia al alta y la incidencia de secuelas, y 4) las deficiencias en el funcionamiento del plan.

\section{Pacientes y método}

\section{Tipo de estudio}

Se realizó un estudio observacional prospectivo, tipo registro de casos, durante un período de 12 meses consecutivos, del 1 de mayo de 2007 al 1 de mayo de 2008, de pacientes en los que se activó el plan de RCP hospitalario por presentar una PCR.

\section{Lugar de estudio}

El estudio se llevó a cabo en el Hospital Juan Ramón Jiménez (HJRJ) de Huelva. Se trata de un Hospital general medicoquirúrgico de nivel 2 , de referencia provincial para Nefrología, Neurocirugía y Cirugía Vascular, con una población asignada propia y de referencia de 261.755 y 496.508 habitantes, respectivamente, 22.523 ingresos anuales y 610 camas durante el período de estudio.

\section{Organización de la asistencia a la parada cardiorrespiratoria}

Desde el 1 de mayo de 2007 el tratamiento del paro cardíaco se realiza según un plan hospitalario de RCP y soporte vital $^{19}$, común a todas las UH. El plan se elaboró durante los 6 meses previos de acuerdo con el diseño que muestra la figura 1. El objetivo fundamental consistía en implantar la estrategia de actuación denominada "cadena de supervivencia", formada por 4 eslabones secuenciales, interrelacionados entre sí y con tiempos de respuesta prefijados: la alarma inmediata ante un posible paro, el inicio precoz de la RCP básica sin demora en menos de $1 \mathrm{~min}$, la DF temprana antes de los 4 min y la RCP avanzada (RCPA) precoz en menos de $8 \mathrm{~min}$. La organización de esta cadena asistencial requería 2 líneas de trabajo principales: que cada planta fuera autónoma en la RCP inmediata y que la RCPA se aplicara también rápidamente y por personal cualificado.

La descentralización de la RCP implicó considerar al personal de enfermería de la planta como el primer interviniente en la PCR y, por consiguiente, impulsar y programar su formación en RCP instrumental (RCPI) y RCP avanzada (RCPA), comenzando por los responsables de la supervisión y las UH de mayor riesgo a priori, como Medicina Interna y especialidades, Cirugía Vascular y Neurocirugía. Al mismo tiempo, se adquirieron desfibriladores externos semiautomáticos (DESA) para aquellas UH que no disponían de ellos y se normalizaron los carros de RCP en su localización, composición y organización del material. Los fármacos se dispusieron en maletines precintados, identificados por planta con un código y fácilmente transportables, dentro de compartimentos individuales etiquetados en el exterior y en su interior ${ }^{19}$; la caducidad se controlaba en una base de datos específica por el servicio de farmacia hospitalaria, que también se encargaba de restituir inmediatamente el maletín en caso de utilización.

Para continuar con la RCP iniciada por el personal de enfermería se constituyó el equipo de soporte vital avanzado (ESVA) integrado por los siguientes componentes (fig. 2): 1) la supervisora de guardia; 2) el médico intensivista si la PCR ocurría en servicios quirúrgicos (cirugía y traumatología), servicios medicoquirúrgicos (urología y oftalmología) o servicios centrales (radiología y laboratorios) o internista si sucedía en servicios médicos (medicina interna y especialidades, nefrología y hematología); 3) el facultativo de guardia propio del servicio, y 4)

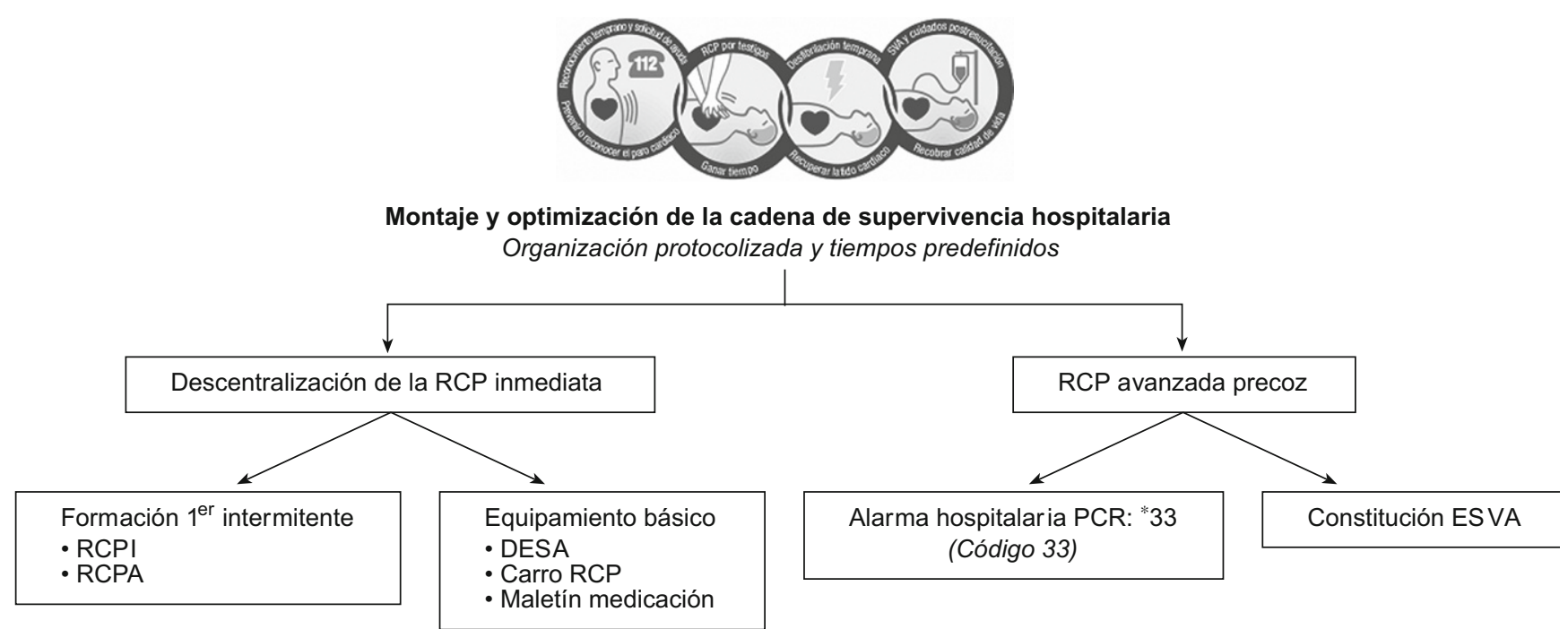

Figura 1 Diseño del plan de resucitación cardiopulmonar del Hospital Juan Ramón Jiménez de Huelva. DESA: desfibrilador externo semiautomático; ESVA: equipo de soporte vital avanzado; RCPA: resucitación cardiopulmonar avanzada; RCPI: resucitación cardiopulmonar instrumental. 


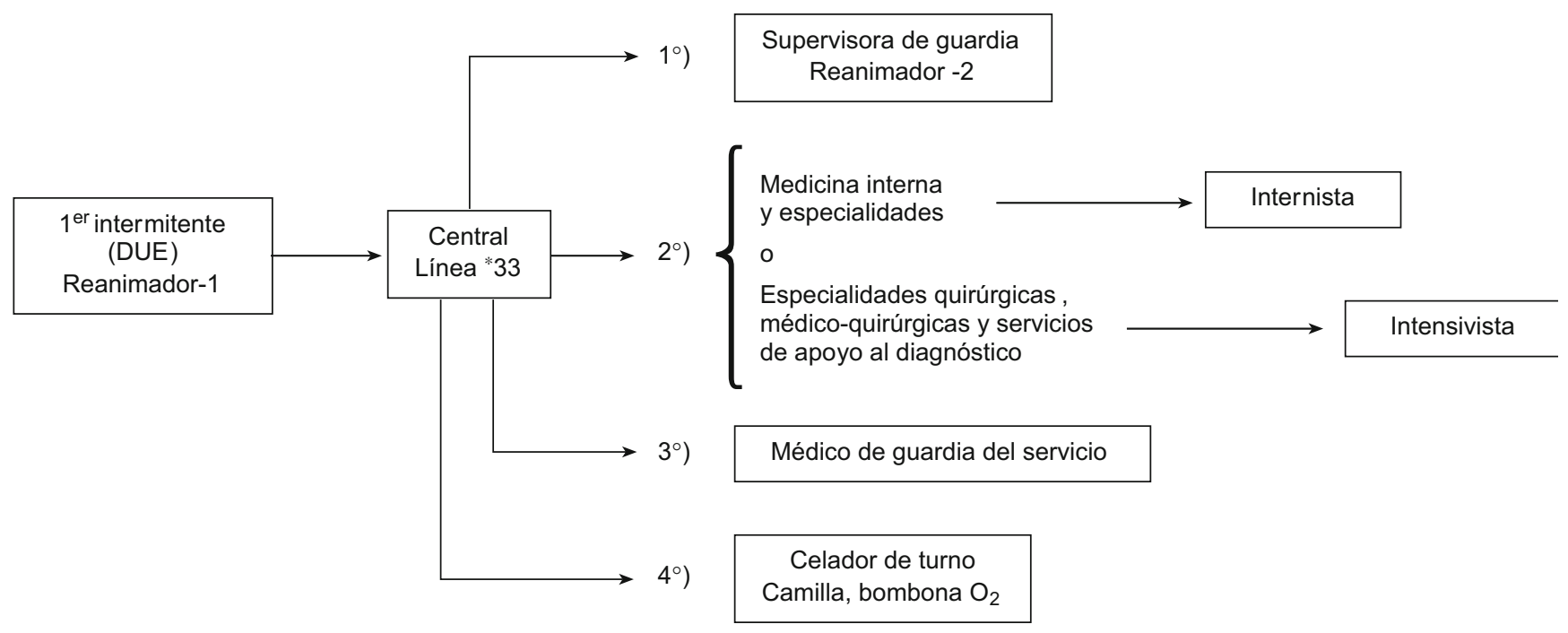

Figura 2 Composición del equipo de soporte vital avanzado y orden de activación. DUE: diplomado universitario de enfermería.

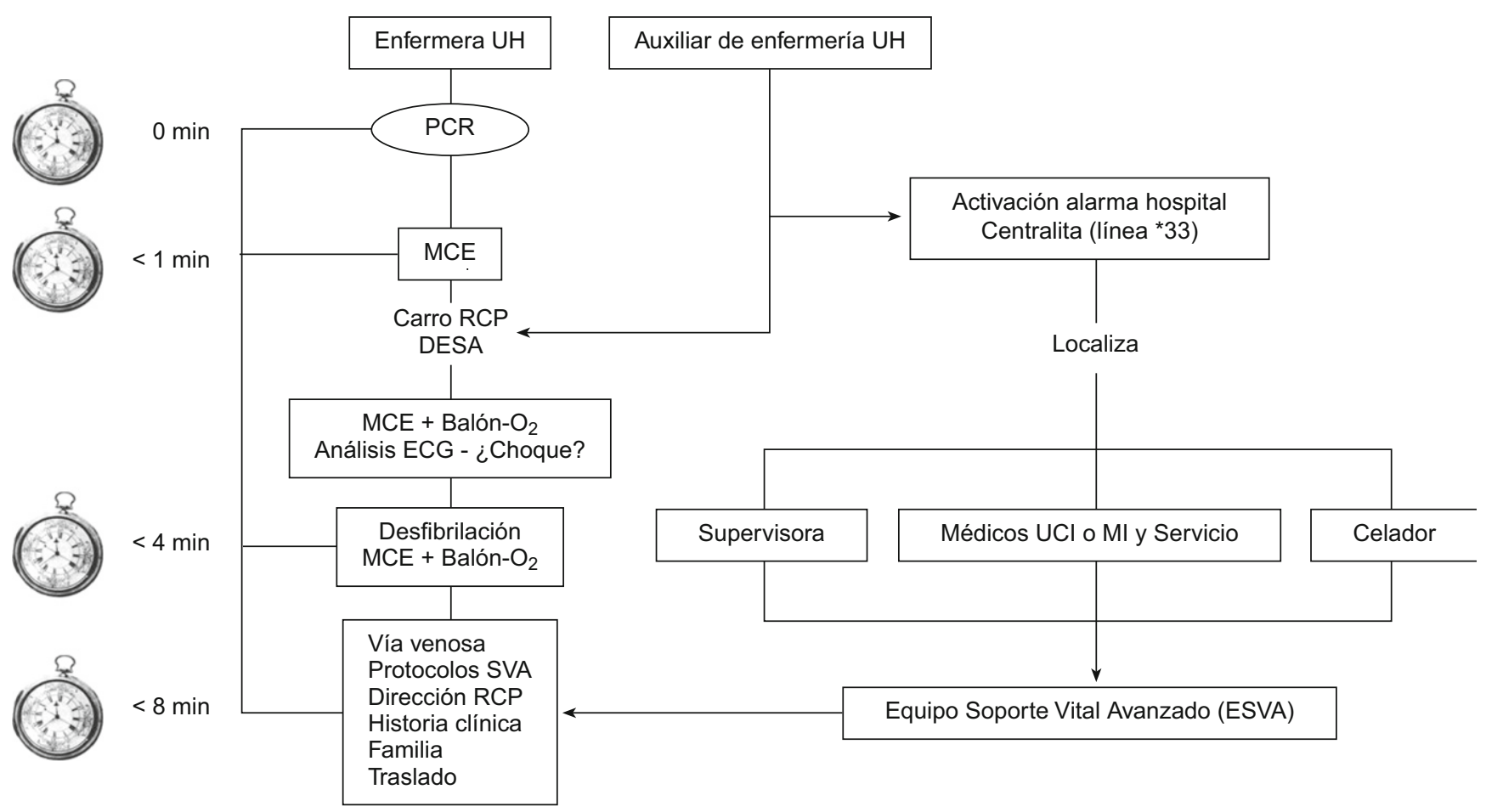

Figura 3 Esquema de organización del protocolo hospitalario de asistencia a la parada cardiorrespiratoria (PCR). DESA: desfibrilador externo semiautomático; ESVA: equipo de soporte vital avanzado; MCE: masaje cardíaco externo; MI: medicina interna; RCP: resucitación cardiopulmonar; SVA: soporte vital avanzado; UCI: unidad de cuidados intensivos; UH: unidad de hospitalización.

el responsable del personal celador de turno, que se desplazaba con una camilla de traslado y una bombona de oxígeno.

La central telefónica activaba y movilizaba al lugar del episodio este ESVA, en el orden expuesto, cuando se llamaba al número telefónico de alerta hospitalaria de parada (*33 [asterisco treinta y tres]) y se comunicaba que había un "código 33" en una planta y un servicio determinados. Opcionalmente, el intensivista también podía requerirse al escenario si el internista lo consideraba necesario.
El protocolo hospitalario de asistencia a la PCR en una UH se esquematiza en la figura 3.

\section{Criterios de inclusión y exclusión}

En el presente estudio se incluyó a los enfermos ingresados en las UH no monitorizadas, atendidos por una supuesta PCR mediante la activación de la alarma de paro del hospital (“código 33"). No estaban contemplados en el plan de RCP 
y, por tanto, se excluyó a los pacientes de urgencias, $\mathrm{UCl}$, quirófanos y reanimación postoperatoria.

\section{Recogida de datos}

Tras la RCP, de forma sistemática, la enfermera de la propia planta y el médico del ESVA cumplimentaban una hoja de recogida de datos previamente elaborada en la que se registraron las siguientes variables, según el "estilo Utstein"20,21, agrupadas en 3 apartados:

1. Relacionadas con las características de los pacientes: edad y sexo del enfermo, fecha de ingreso, motivo de ingreso y existencia de orden de no RCP.

2. Relacionadas con el episodio de la PCR: activación del código de parada (activación por PCR, activación con orden de no RCP y falsa alarma), fecha y hora de la PCR, turno (mañana: de 08.00 a 15.00; tarde: de 15.00 a 22.00, y noche: de 22.00 a 08.00), servicio y $U H$, enfermedad principal, causa y primer ritmo cardíaco monitorizado de la PCR, tiempo transcurrido hasta el inicio de la RCP básica, primer interviniente (enfermera, médico especialista o médico residente), tiempo transcurrido hasta la llegada del primer componente del ESVA, ritmo del primer ECG ("desfibrilable" o "no desfibrilable”), tiempo transcurrido hasta la primera DF, aislamiento de la vía aérea, duración de la RCP, fármacos empleados e intervenciones especiales (drenaje pleural, drenaje pericárdico, aporte de volumen, aporte de potasio, trombolisis y antídotos).

3. Relacionadas con los resultados: fallecimiento o supervivencia al suceso (considerada como tal la recuperación de la circulación espontánea durante más de $20 \mathrm{~min}$ ), estado al alta hospitalaria, situación funcional de los pacientes supervivientes al alta hospitalaria, a los 6 meses y al año, valorada por encuesta telefónica mediante la escala de categoría de función cerebral (CFC) (Glasgow-Pittsburgh Cerebral Perfomance Categories) ${ }^{22}$.

También se recogieron variables relacionadas con datos de control interno, como activación adecuada del código de parada ("código 33"), funcionamiento de los teléfonos, indicación correcta del lugar de la PCR, ubicación incorrecta o deficiencias en el carro de RCP (ausencia de revisión, falta de precintado, de medicación o de material) y desfibrilador no localizable en el sitio especificado. Estos datos individuales se introducían en un registro hospitalario de PCR con soporte informático Microsoft Office Excel para MacOS 2004.

\section{Resultados}

Durante el período analizado se registraron un total de 73 activaciones de la alarma hospitalaria ("código 33"), de las que 65 fueron por PCR, lo que representa una incidencia de 0,11 paradas/camas o 2,90 paradas por cada 1.000 pacientes ingresados en UH convencionales. Las 8 falsas llamadas se debieron a síncope (3), a estado poscrítico (2), a coma hipercápnico (2) y a obstrucción de vía aérea superior (1). Los resultados más relevantes del estudio, agrupados en las 4 categorías de variables recogidas, se resumen en las tablas 1 y 2 .

1. Características de los pacientes (tabla 1)

El $60 \%$ fueron hombres, con un rango de edad de 30-91 años y una edad media de 69,6 años en hombres y de 73,4 años en mujeres, con un claro predominio de los pacientes de 70 o más años. Con respecto a la distribución de las PCR en el hospital, el 65\% ocurrió en salas médicas (Medicina Interna y especialidades), preferentemente en Nefrología y Respiratorio, y el $31 \%$ en plantas quirúrgicas, especialmente en Cirugía Vascular. La enfermedad principal fue cardíaca $(45 \%)$, respiratoria $(37 \%)$, renal $(8 \%)$, infecciosa $(6 \%)$ y neurológica $(4 \%)$. Las causas más frecuentes de la parada fueron la insuficiencia respiratoria aguda (37\%), la insuficiencia cardíaca congestiva (21\%), el edema agudo del pulmón $(9 \%)$, el shock séptico $(6 \%)$ y la sepsis $(3 \%)$. Los episodios de PCR ocurrieron prematuramente en el primer día de ingreso $(17 \%)$, en la primera semana $(38 \%)$ y cuando el enfermo llevaba más de 7 días ingresado (45\%).

2. Episodio de la parada cardiorrespiratoria (tabla 2)

El ritmo cardíaco inicial más frecuente de la parada fue asistolia en 45 pacientes (74\%), seguidos de fibrilación ventricular (FV) en 11 pacientes (18\%) y actividad eléctrica sin pulso (AESP) en 5 pacientes $(8 \%)$. No hubo ningún caso de taquicardia ventricular sin pulso. La FV fue más frecuente en Nefrología y la asistolia y la AESP en las salas de Medicina Interna y Cirugía. En total, el primer ritmo eléctrico fue "no desfibrilable" en el $83 \%$ de los casos y "desfibrilable" en el 17\% restante.

Los turnos horarios en los que se produjeron más PCR fueron los de mañana (44\%) y noche (33\%) y más en días laborables $(58 \%)$ que en fines de semana y festivos (42\%).

El primer interviniente en la PCR fue una enfermera en 48 casos (79\%), un médico especialista en 8 casos (13\%) y un médico residente en 5 casos (8\%). La RCP básica se realizó siempre en menos de 1 min y la RCPA se inició por el ESVA entre 50 s y $15 \mathrm{~min}$, y el tiempo de respuesta fue inferior a 4 min en el $75 \%$ de las ocasiones, en menos de $8 \mathrm{~min}$ en el $94 \%$ y en más de 8 min sólo en un $6 \%$. En el $92 \%$ de las PCR por FV se consiguió desfibrilar en menos de 2 min y en el restante $8 \%$ se consiguió entre 2 y $4 \mathrm{~min}$.

3. Resultados finales de la parada cardiorrespiratoria Los resultados, expuestos según el "estilo Utstein", se exponen en la figura 4. De los 65 pacientes con PCR documentada, en 61 casos se aplicó la RCP y en 4 no se aplicó por constancia de una orden expresa verbal o escrita de no resucitación en la historia clínica. De los 11 pacientes con FV, 9 (82\%) recuperaron la circulación espontánea y a 5 de ellos (55\%) se los dio de alta del hospital. De los 50 enfermos con asistolia o AESP, 27 (54\%) se recuperaron de la PCR y 18 (36\%) fueron altas hospitalarias. Del total de pacientes atendidos con maniobras de RCP, sobrevivieron a la PCR 36 (59\%) y se dio de alta del hospital con vida a 23 , lo que representa una supervivencia global del $38 \%$. El $87 \%$ de los pacientes dados de alta sobrevivía al año y no tenía secuelas neurológicas o incapacidades graves, ya que el $78 \%$ se mantenía en una CFC 1 o 2 (tabla 3). 
Tabla 1 Características generales de los pacientes en los que se activó la alarma hospitalaria de parada cardiorrespiratoria

\begin{tabular}{|c|c|c|c|}
\hline & $\begin{array}{l}\text { Total de enfermos, } \\
\text { n (\%) }\end{array}$ & $\begin{array}{l}\text { Recuperación de la } \\
\text { circulación espontánea, n (\%) }\end{array}$ & $\begin{array}{l}\text { Vivos al alta hospitalaria, } \\
\text { n (\%) }\end{array}$ \\
\hline \multicolumn{4}{|l|}{ Edad, años } \\
\hline$\leq 70$ & $26(40)$ & $17(65)$ & $13(50)$ \\
\hline$>70$ & $39(60)$ & $19(49)$ & $10(26)$ \\
\hline \multicolumn{4}{|l|}{ Sexo } \\
\hline Varones & $39(60)$ & $20(51)$ & $13(33)$ \\
\hline Mujeres & $26(40)$ & $16(49)$ & $10(38)$ \\
\hline \multicolumn{4}{|l|}{ Lugar de la PCR } \\
\hline Médicas & $42(65)$ & $20(47)$ & $10(24)$ \\
\hline Medicina Interna & 23 & & \\
\hline Nefrología & 10 & & \\
\hline Neumología & 7 & & \\
\hline Cardiología & 2 & & \\
\hline Oncología & 1 & & \\
\hline Quirúrgicas & $20(31)$ & $14(70)$ & $11(55)$ \\
\hline Cirugía vascular & 11 & & \\
\hline Cirugía general & 6 & & \\
\hline Neurocirugía & 3 & & \\
\hline Otras & $3(4)$ & $2(67)$ & $2(67)$ \\
\hline Psiquiatría & 1 & & \\
\hline Urología & 1 & & \\
\hline Ginecología & 1 & & \\
\hline \multicolumn{4}{|l|}{ Enfermedad principal } \\
\hline Cardíaca & $29(45)$ & 17 (59) & $10(34)$ \\
\hline Respiratoria & $24(37)$ & $15(62)$ & $11(45)$ \\
\hline Renal & $5(8)$ & $2(40)$ & $0(0)$ \\
\hline Infección & $4(6)$ & $1(25)$ & $1(25)$ \\
\hline Neurológica & $3(4)$ & $1(33)$ & $1(25)$ \\
\hline \multicolumn{4}{|l|}{ Causas de la PCR } \\
\hline IRA & $24(37)$ & $15(62)$ & $8(33)$ \\
\hline ICC & $23(35)$ & $10(43)$ & $6(26)$ \\
\hline EAP & $6(9)$ & $4(67)$ & $4(67)$ \\
\hline Shock séptico & $4(6)$ & $2(50)$ & $1(25)$ \\
\hline Sepsis & $2(3)$ & $1(50)$ & $1(25)$ \\
\hline Hiperpotasemia & $2(3)$ & $2(100)$ & $1(50)$ \\
\hline Shock anafiláctico & $1(2)$ & $1(100)$ & $1(100)$ \\
\hline TEP & $1(2)$ & $1(100)$ & $1(100)$ \\
\hline Sin especificar & $2(3)$ & $0(0)$ & $0(0)$ \\
\hline \multicolumn{4}{|c|}{ Estancia previa a la $P C R$} \\
\hline$<24 \mathrm{~h}$ & $11(17)$ & $5(45)$ & $3(27)$ \\
\hline 1-7 días & $25(38)$ & $16(64)$ & $11(44)$ \\
\hline$>1$ semana & $29(45)$ & $15(51)$ & $9(31)$ \\
\hline
\end{tabular}

EAP: edema agudo del pulmón; ICC: insuficiencia cardíaca congestiva; IRA: insuficiencia respiratoria aguda; PCR: parada cardiorrespiratoria; TEP: tromboembolia pulmonar.

4. Control interno

Todas las falsas activaciones de la alerta hospitalaria de PCR se produjeron en UH de Cirugía y se debieron a síncope (3), a estado poscrítico (2), a obstrucción de la vía aérea superior (1) y a coma hipercápnico (2). En una ocasión, el carro de RCP no estaba situado en el lugar adecuado y en otra ocasión no se había revisado el material de la vía aérea. Con respecto a la activación del ESVA, una vez se localizó al médico intensivista por el teléfono de la guardia y no por el específico del "código 33" y otra vez no se avisó al médico de guardia.

\section{Discusión}

Los resultados del primer año de funcionamiento del plan de RCP del HJRJ demuestran su viabilidad y la capacidad para aplicar las recomendaciones actuales de 
Tabla 2 Características del episodio de parada cardiorrespiratoria de los pacientes con intento de resucitación cardiopulmonar

\begin{tabular}{|c|c|c|c|}
\hline & $\begin{array}{l}\text { Total de enfermos, } \\
\text { n (\%) }\end{array}$ & $\begin{array}{l}\text { Recuperación de la } \\
\text { circulación espontánea, n (\%) }\end{array}$ & $\begin{array}{l}\text { Vivos al alta hospitalaria, } \\
\text { n (\%) }\end{array}$ \\
\hline \multicolumn{4}{|c|}{ Ritmo cardíaco inicial } \\
\hline Asistolia & $45(74)$ & $25(55)$ & $16(35)$ \\
\hline FV & $11(18)$ & $9(82)$ & $5(45)$ \\
\hline AESP & $5(8)$ & $2(40)$ & $2(40)$ \\
\hline \multicolumn{4}{|l|}{ Turno horario } \\
\hline Mañana & $27(44)$ & $14(52)$ & $11(41)$ \\
\hline Tarde & $14(23)$ & $9(64)$ & $7(50)$ \\
\hline Noche & $20(33)$ & $11(55)$ & $8(40)$ \\
\hline \multicolumn{4}{|c|}{ Día de la semana } \\
\hline$L-V$ & $36(58)$ & $21(58)$ & 14 (39) \\
\hline S-D-F & $25(42)$ & $15(60)$ & $9(36)$ \\
\hline \multicolumn{4}{|c|}{ Primer interviniente } \\
\hline Enfermera & $48(79)$ & $28(58)$ & $18(37)$ \\
\hline Facultativo & $8(13)$ & $5(62)$ & $3(37)$ \\
\hline Residente & $5(8)$ & $3(60)$ & $2(40)$ \\
\hline \multicolumn{4}{|c|}{ Tiempo de RCP básica*, min } \\
\hline$<1$ & $61(100)$ & $36(55)$ & $23(35)$ \\
\hline \multicolumn{4}{|c|}{ Tiempo de llegada del ESVA, min } \\
\hline$<4$ & $49(75)$ & 29 (59) & $19(65)$ \\
\hline $4-8$ & 12 (19) & $6(50)$ & $4(66)$ \\
\hline$>8$ & $4(6)$ & $1(25)$ & $0(0)$ \\
\hline \multicolumn{4}{|c|}{ Tiempo de desfibrilación, min } \\
\hline$\leq 2$ & $10(92)$ & $8(80)$ & $4(50)$ \\
\hline $3-4$ & $1(8)$ & $1(100)$ & $1(100)$ \\
\hline \multicolumn{4}{|c|}{ Duración de la $R C P$, min } \\
\hline$\leq 30$ & $26(43)$ & $16(61)$ & $12(46)$ \\
\hline$>30$ & $35(57)$ & $20(57)$ & $11(31)$ \\
\hline
\end{tabular}

la RCP hospitalaria7. Al mismo tiempo, ha permitido mediante el establecimiento de un sistema de registro conocer la incidencia de PCR en nuestro medio, las causas y los mecanismos que la desencadenan, las áreas hospitalarias de mayor riesgo y la eficacia de la organización asistencial propuesta.

En nuestro hospital, la incidencia de PCR registrada en este primer año (2,9 paradas por cada 1.000 pacientes ingresados y 0,11 por cama hospitalaria y año) está dentro del rango bajo de los registros americanos y europeos ${ }^{13,14,23}$, que refieren de 1 a 5 paros por cada 1.000 admisiones y 0,17 por cama y año, y también es inferior a las series publicadas en nuestro país por Fontanals et $\mathrm{al}^{24}(5,1$ por cada 1.000 ingresos en $\mathrm{UH}$ convencionales) y Colmenero et $\mathrm{al}^{25}$ (3,7 por cada 1.000 ingresos, incluyendo áreas monitorizadas, como urgencias, $\mathrm{UCl}$, quirófano o reanimación).

El porcentaje de falsas activaciones (12\%) fue inferior al $15,1-20,5 \%$ publicado en otras series hospitalarias ${ }^{24-26}$. La totalidad se produjo en unidades quirúrgicas, y se detectó un área de posible mejora en la formación del personal sanitario en RCP básica. Probablemente, en alguna de ellas, como en el caso de la obstrucción de la vía aérea superior, a pesar de que el diagnóstico de PCR no fue correcto, la intervención del ESVA fue decisiva. No obstante, la pretensión del plan no era atender a las urgencias, para lo que hay equipos de guardia específicos en el hospital, sino a la PCR, por lo que el control de estas alertas inadecuadas es imprescindible para no invalidar el plan por pérdida de la fiabilidad de la alarma hospitalaria. Por esto, después de cada falso "código 33" se hacían intervenciones concretas de revisión del protocolo con los responsables asistenciales de la unidad hospitalaria.

La supervivencia inmediata de los pacientes reanimados en el hospital es muy variable, y se han publicado cifras del 36,8 al $49,3 \%{ }^{26-30}$. En nuestro hospital fue más alta $(59 \%)$, igual que la de las 2 series españolas mencionadas ${ }^{24,25}$. También el porcentaje global de altas hospitalarias fue elevado (38\%), similar al del Hospital Clinic de Barcelona 


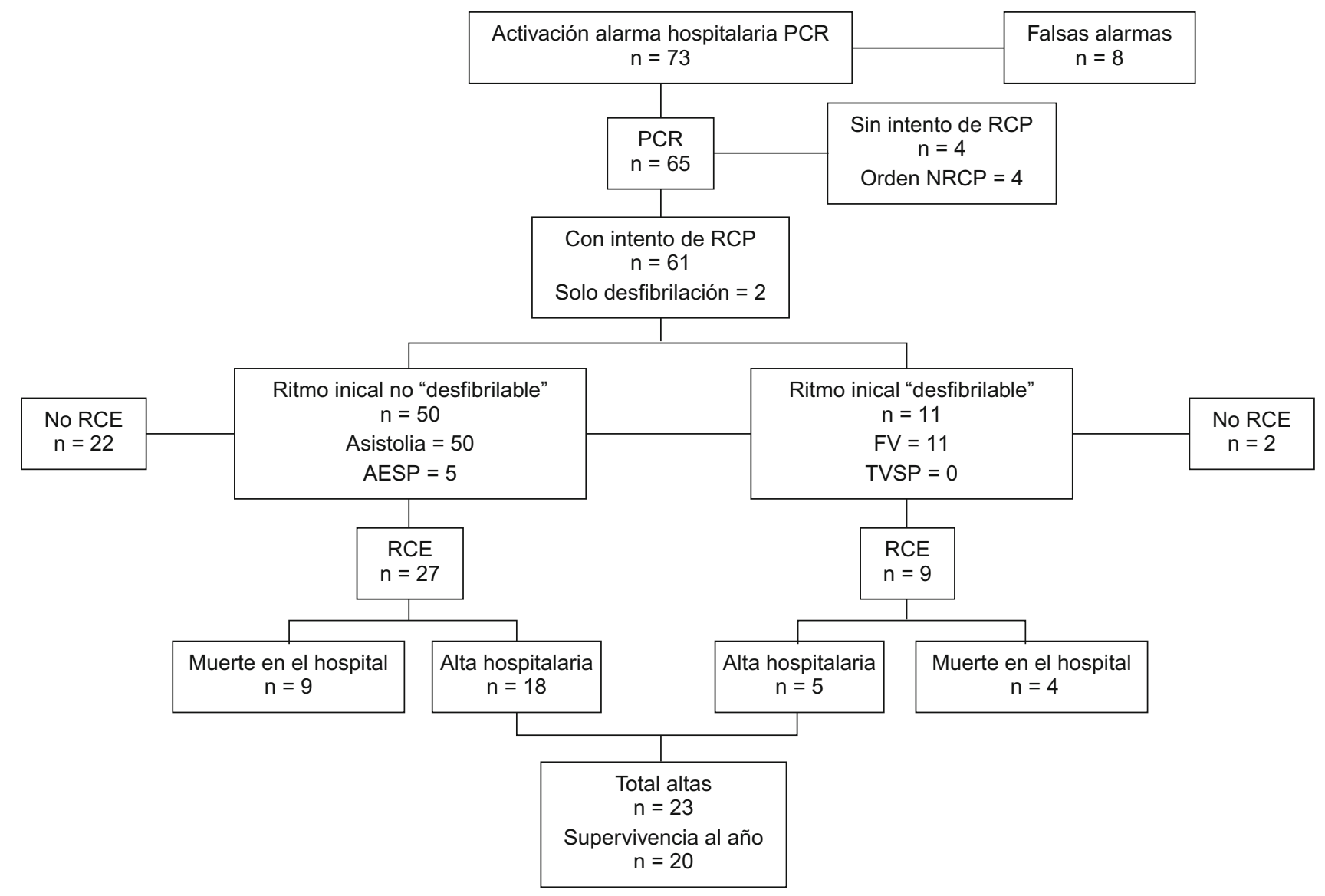

Figura 4 Diagrama de resultados según el “estilo Utstein”. AESP: actividad eléctrica sin pulso; FV: fibrilación ventricular; PCR: parada cardiorrespiratoria; RCE: recuperación de la circulación espontánea durante más de 20 min; RCP: resucitación cardiopulmonar; TSVP: taquicardia ventricular sin pulso.

Tabla 3 Categorías de función cerebral en pacientes supervivientes al alta hospitalaria

\begin{tabular}{llll}
\hline Categoría función cerebral & $\begin{array}{l}\text { Función cerebral } \\
\text { al alta, } \mathbf{n}(\%)\end{array}$ & $\begin{array}{l}\text { Función cerebral a los } 6 \\
\text { meses, } \mathbf{n}(\%)\end{array}$ & $\begin{array}{l}\text { Función cerebral a los 12 } \\
\text { meses, } \mathbf{n}(\%)\end{array}$ \\
\hline 1. Buena función & $21(91)$ & $18(78)$ & $16(69)$ \\
2. Incapacidad moderada & $1(4,5)$ & $3(13)$ & $2(9)$ \\
3. Incapacidad grave & $1(4,5)$ & $1(4,5)$ & $2(9)$ \\
4. Coma, estado vegetativo & - & - & - \\
5. Muerte & - & $1(4,5)$ & $3(13)$ \\
\hline
\end{tabular}

$(36 \%)^{24}$ y al del hospital sueco de Shalgrenska ${ }^{26}$ y superior al que comunican la mayoría de los estudios (20\%), aunque el rango depende del área hospitalaria donde se presente la $\mathrm{PCR}^{31,32}$ : en urgencias, del 22,8 al $30,3 \%$; en la $\mathrm{UCl}$, del 15,5 al $23,7 \%$; en salas con telemetría, del 19,8 al $25,2 \%$, y en salas generales, del 10,8 al $13,2 \%$. La mayoría $(87 \%)$ de los pacientes dados de alta del hospital sobrevivía a los 12 meses con buena CFC (el 78\% en categoría 1 y 2 ).

Estos resultados indican la necesidad de disponer de un plan estructurado de atención a las PCR para mejorar la supervivencia general y reducir las secuelas posparada. En nuestro Hospital, históricamente la asistencia a la PCR no estaba protocolizada y mostraba muchas deficiencias y carencias (tabla 4), como una atención desorganizada a la
PCR en los diferentes servicios, la ausencia de órdenes de no $\mathrm{RCP}$, el equipamiento electromédico disperso, los carros de RCP sin normalizar ni revisar, la insuficiente formación del personal sanitario y la falta de registros. Esta situación era similar a la de la mayoría de los hospitales, de tal manera que en el año 2005 se consideraba muy difícil que los hospitales españoles superaran la acreditación si se les aplicaban los estándares de la Joint Commission for Accreditation of Healthcare Organizations (JCAHO) ${ }^{7,33}$.

Existen evidencias suficientes de que la supervivencia de la parada cardíaca depende esencialmente de la rapidez con que se actúe en cada uno de los eslabones o las fases de la cadena de supervivencia ${ }^{34}$. El concepto actual de actividad de la UCl "puertas afuera" (outdoor) o "medicina intensiva 
Tabla 4 Características de la atención a la parada cardiorrespiratoria hospitalaria previas al desarrollo del plan de resucitación cardiopulmonar del Hospital Juan Ramón Jiménez en las unidades de hospitalización

1. Atención a la PCR no organizada

- Detección tardía de la PCR

- Llamada al médico de guardia o al intensivista como primer interviniente

- Comienzo de la RCP básica con retraso

- Ausencia de equipos de RCP avanzada

- Demora importante en la desfibrilación

2. Inexistencia de órdenes de no RCP

3. Deficiente equipamiento electromédico y fungible

- Falta de desfibrilador en muchas plantas

- Carro de RCP habitualmente no estructurado ni revisado

4. Insuficiente formación del personal sanitario

- Ausencia de protocolos homogéneos de PCR

- Maniobras de RCP no estandarizadas ni actualizadas

- Ausencia de enseñanza reglada periódica de la RCP

5. Carencia de datos, registros e información

6. Familia desconcertada y desinformada, sin referentes

PCR: parada cardiorrespiratoria; RCP: reanimación cardiopulmonar.

fuera de la UCI" (outreach services) es el que ha impulsado en algunos hospitales la creación de equipos de urgencias médicas intrahospitalario, orientados a la prevención y al tratamiento de situaciones de riesgo que se consideran avisos precoces de la $P C R^{35,36}$. El fundamento para su desarrollo es la constatación de que entre un 50 y un $84 \%$ de los pacientes que presentan parada cardíaca en el hospital ha presentado horas antes alguna inestabilidad fisiológica que no se reconoce, pasa desapercibida o se trata de forma incorrecta 0 ineficaz ${ }^{37}$. Aunque diversos estudios han mostrado resultados discordantes o controvertidos con respecto a su eficacia ${ }^{38,39}$, es importante destacar, dentro de la optimización de los eslabones de la cadena de super vivencia, la formación y la divulgación entre el personal sanitario de sistemas de alerta basados en la vigilancia de parámetros fisiológicos cuya alteración permita identificar a los pacientes en riesgo de paro cardíaco $^{40,41}$. En un estudio reciente de Ehlenbach et $\mathrm{al}^{42}$, en el que se analizan las PCR hospitalarias en mayores de 65 años desde 1992 hasta 2005, se comprueba que la supervivencia no cambia durante esos 14 años a pesar de incrementarse el porcentaje de pacientes que reciben RCP. Por consiguiente, puesto que es difícil mejorar la supervivencia del paro cardíaco hospitalario, las medidas encaminadas a su prevención pueden contribuir a decrecer la mortalidad.

En nuestro plan, el objetivo asistencial del ESVA no era la prevención de la PCR, sino su tratamiento una vez instaurada. Aunque en la mayoría de las experiencias realizadas el equipo de resucitación o de soporte vital estaba integrado exclusivamente por enfermeras de la $\mathrm{UCl}$ y médicos intensivistas o anestesistas, en nuestro Hospital la composición del ESVA respondía a la filosofía de integrar en el plan al personal propio de las UH y del servicio. La implicación de las supervisoras se consideró crucial por varios motivos: en primer lugar, porque si el plan debía apoyarse básicamente en la capacitación de enfermería, la supervisora era la figura más indicada por su posición jerárquica y de liderazgo para comprometer a los integrantes de su unidad y, en segundo lugar, porque su continuidad asistencial por turno garantizaba siempre un segundo reanimador entrenado en el escenario de la PCR. Se prefirió también ampliar su composición a los internistas y a sus especialidades por las siguientes razones: su formación médica y experiencia aseguraban un dominio suficiente en las técnicas de RCP, el conocimiento del diagnóstico y el pronóstico de la mayoría de sus pacientes podría evitar resucitación innecesarias mediante el desarrollo de órdenes de no realizar RCP y su proximidad física en turno ordinario y jornada de guardia a las UH posibilitaba una llegada rápida al lugar del episodio. En estas circunstancias, el intensivista podía acudir, pero no en primera instancia, sino a requerimiento del especialista médico. En el resto de las unidades quirúrgicas o medicoquirúrgicas, aunque se movilizaba al facultativo de guardia, el intensivista acudía en primera instancia a la PCR y asumía la dirección de la RCP. Completaba el equipo el celador con el material básico de transporte (camilla específica, cilindro de oxígeno y soporte para el monitor desfibrilador) para no demorar el traslado de los pacientes supervivientes a la $\mathrm{UCl}$.

La incidencia de PCR fue mayor en hombres $(60 \%)$ que en mujeres (40\%). Si bien es controvertida la influencia de la edad en el pronóstico en nuestro medio, como en otros estudios, no influyó en la mortalidad. Aunque las paradas fueron más frecuentes en turno de mañana (44\%) y en días laborables (58\%), ni la presentación durante la tarde $(23 \%)$, la noche $(33 \%)$ o en fines de semana $(42 \%)$ fueron factores determinantes de mortalidad. Sin embargo, en otros ámbitos hospitalarios, probablemente con sistemas organizativos asistenciales diferentes ${ }^{29,43}$, se ha constatado en el turno de tarde-noche con respecto al de mañana una significativa menor supervivencia inmediata (el 44,7 versus el $51,1 \%$ ) y a las $24 \mathrm{~h}$ (el 28,9 versus el $35,4 \%$ ) y una menor tasa de evolución neurológica favorable (el 11,0 versus el $15,2 \%)^{43}$. En este estudio ${ }^{43}$ también se comprobó que la eficacia de la RCP era menor durante los fines de semana que en días ordinarios, con supervivencias del 17,4 y el $20,6 \%$, respectivamente. Este hecho podría interpretarse como signo de una respuesta más homogénea del plan de RCP del HJRJ, independientemente de los recursos humanos y de los ritmos de trabajo del centro, muy variable según la hora y el día de la semana.

Un porcentaje importante $(17,5 \%)$ de PCR que ocurrieron antes de las $24 \mathrm{~h}$ de ingreso, probablemente por no reconocer la gravedad del paciente o quizás por la ubicación del enfermo en un área asistencial inadecuada. Como se ha señalado anteriormente, muchas de las PCR que ocurren en el hospital se pueden prevenir si se reconocen determinados signos de alerta que pueden aparecer incluso 6-8 h antes. Se han publicado algunas escalas, cuantitativas o cualitativas, que estimarían el grado de riesgo del paciente para presentar un paro y se ha recomendado su uso por el personal de enfermería de las $\mathrm{UH}^{44,45}$.

Es una evidencia que el tiempo transcurrido entre la PCR y el inicio de las maniobras de RCP, la DF y el aislamiento de la 
vía aérea es fundamental para la supervivencia inmediata (recuperación de la circulación espontánea), la supervivencia a medio plazo (alta hospitalaria) y la supervivencia tardía (6-12 meses). El plan garantizó que la RCP básica se realice siempre sin demora, en menos de $1 \mathrm{~min}$, a causa de la formación previa del personal de enfermería de las plantas, lo que permitió que actuara como primer interviniente en el $79 \%$ de las ocasiones y que la DF se realizara en el $82 \%$ de los casos en menos de 2 min y siempre antes de los $4 \mathrm{~min}$. Similar experiencia ha comunicado el St. JosefHospital de Bockum (Alemania) ${ }^{46}$, que instauró un programa de implantación y entrenamiento específico en DESA orientado a la formación de primeros intervinientes, fundamentalmente enfermeras, en los que se consiguió desfibrilar en 2,1 min (rango: 1,0-4,5) los 18 casos de FVTV de las 27 PCR atendidas, con un porcentaje de recuperación del $88,9 \%$ y de altas hospitalarias del $55,6 \%$. No obstante, otros estudios ${ }^{47-49}$ de ámbitos asistenciales diferentes ponen de manifiesto que incluso en la $\mathrm{UCl}$ o en las salas con monitorización, hasta en el 21,9 y el $37,4 \%$ de los pacientes ingresados que presentan una PCR, la DF puede retrasarse más de $2 \mathrm{~min}$, especialmente si sucede fuera del horario de mañana en días laborables, siendo la supervivencia en la DF precoz de un $39 \%$ y en la tardía de un $22 \%$, con diferencia estadísticamente significativa. En el reciente estudio de Chan et $\mathrm{al}^{50}$, en el que analizan 7.479 paros cardíacos de adultos en 200 hospitales inscritos en el Registro Nacional de $R C P$, se pone de manifiesto la influencia en la mortalidad de la PCR hospitalaria del retraso en la aplicación de la DF y cómo éste puede variar de un hospital a otro. En entre un 2,4-50,9\% de hospitales el choque eléctrico se difería más de 2 min y la mayor supervivencia (rango: 5,3-49,6\%) se correspondía con un menor tiempo de respuesta. En nuestro centro, la alerta de PCR por un teléfono y código único y exclusivo, la formación en RCPI y RCPA de las enfermeras de las plantas y la movilización del ESVA por una sola persona de la central hospitalaria, según un protocolo predefinido, pudieron contribuir en gran medida a la consecución de estos tiempos idóneos.

Como en trabajos recientemente publicados, nuestro estudio también puso de manifiesto que la FV es menos frecuente en la PCR hospitalaria que en la extrahospitalaria. Sólo se registró como primer ritmo eléctrico en el $17 \%$ de los casos, superior a la AESP, que se identificó en un 15\% como primer ritmo, y muy inferior a la asistolia detectada en un $68 \%$. Este porcentaje está dentro del rango inferior de lo publicado por otros centros tanto nacionales ${ }^{24,25}$ como europeos o americanos ${ }^{27,28,31}$, con un rango entre el 20-35\%. Esta menor frecuencia de ritmos desfibrilables en la PCR hospitalaria se ha atribuido a que en la comunidad el mecanismo fundamental de la PCR es la isquemia miocárdica, que induciría un paro por trastorno eléctrico (FV), mientras que en el hospital serían fundamentalmente la insuficiencia respiratoria y la sepsis, que provocarían una mayor incidencia de asistolia. Por esto, las políticas de prevención de la PCR en el hospital deberían ir dirigidas a detectar precozmente la hipoxemia, la sepsis grave, la hipotensión y el shock. Como en todos los datos aportados hasta ahora, el pronóstico de la FV o la taquicardia ventricular sin pulso fue mejor que el de la asistolia y la AESP, y la supervivencia inmediata y hospitalaria fue del 81 y el $56 \%$ y del 45,5 y el $20 \%$, respectivamente.
En la supervivencia de los pacientes reanimados de un paro cardíaco influyen, además de los factores relacionados con el sistema organizativo de la resucitación recogidos en este plan, otros vinculados con los cuidados resucitación (cuarto eslabón de la cadena de supervivencia), cuya calidad puede variar de un centro a otro. Estudios recientes ${ }^{51,52}$ señalan diferencias regionales en la mortalidad hospitalaria de los pacientes recuperados de una PCR, en hospitales de distintos estados norteamericanos, y se comprueba una reducción de ésta en algunos centros en los que la implementación de las medidas resucitación se había llevado a cabo en la UCl o críticos.

Las limitaciones iniciales del plan estuvieron relacionadas con el proceso de divulgación y el conocimiento por parte de todo el personal del Hospital, algunas averías técnicas de la línea telefónica, el cumplimiento de las normas dadas para la configuración, la dotación y la ubicación de los carros de RCP y DESA y el control y el seguimiento de los registros de $P C R$. Las órdenes de no RCP, antes inexistentes, han sido también de difícil y lenta implantación, especialmente en áreas quirúrgicas (Cirugía, Traumatología, etc.).

En resumen, el diseño del plan de RCP del HJRJ de acuerdo con las recomendaciones internacionales de la RCP hospitalaria ha demostrado que se puede aplicar y mantener en nuestro entorno, es efectivo con respecto a los datos publicados en la literatura médica, facilita la elaboración de un registro local de paradas cardíacas e identifica poblaciones y áreas de riesgo, lo que permitiría en un futuro implementar políticas de prevención de la PCR hospitalaria.

\section{Conflicto de intereses}

Los autores declaran no tener ningún conflicto de intereses.

\section{Agradecimientos}

Los autores agradecen el interés, el esfuerzo y la dedicación para crear e impulsar el plan de RCP del HJRJ al equipo docente de enfermería formado por María Jesús González, Manuel Bermejo, Francisca Galán y María del Mar Quintero, a las operadoras de la central telefónica, al personal de enfermería de las $\mathrm{UH}$, a los médicos intensivistas y a las direcciones médicas y de enfermería. Sin su colaboración y apoyo no hubiera sido posible su desarrollo.

\section{Bibliografía}

1. Perales Rodríguez de Viguri N, Jiménez Mutillo L, González Díaz G, Álvarez Fernández JA, Medina JC, Ortega J, et al. La desfibrilación temprana: conclusiones y recomendaciones del I Foro de Expertos en Desfibrilación Semiautomática. Med Intensiva. 2003;27:488-94.

2. Álvarez Fernández JA, Álvarez-Mon Soto M, Rodríguez Zapata M. Supervivencia en España de las paradas cardíacas extrahospitalarias. Med Intensiva. 2001;25:236-43.

3. Hodgetts TJ, Kenward G, Vlackonikolis I, Payne S, Castle N, Crouch R, et al. Incidence, location and reasons for avoidable in-hospital cardiac arrest in a district general hospital. Resuscitation. 2002;54:115-23.

4. Skogvoll E, Isern E, Sangolt GK, Gisvold SE. In hospital cardiopulmonary resuscitation: 5 years'incidence and susrvival 
according to the Utstein template. Acta Anaesthesiol Scand. 1999;43:177-84.

5. Jamstreski MS. In-hospital cardiac arrest. Ann Emerg Med. 1993;22:113-7.

6. Pederby MA, Kaye WA, Ornato JP. Cardiopulmonary resuscitation in hospital: A report of 14.720 cardiac arrests from the National Registry of Cardiopulmonary Resuscitation. Resuscitation. 2003;58:297-308.

7. Perales Rodríguez de Viguri N, Pérez Vela JL, Bernat Adell A, Cerdá Vila M, Álvarez Fernández JA, Arribas López P, et al. La resucitación cardiopulmonar en el hospital. Recomendaciones 2005. Med Intensiva. 2005;29:349-56.

8. Berger R, Kelley M. Survival after in-hospital cardiopulmonary arrest of noncritically ill patients. A prospective study. Chest. 1994;106:872-9.

9. Tunstall Pedoe H, Bailey L, Chamberlain DA, Marsden AK, Ward ME, Zidema DA. Survey of 3765 cardiopulmonary resuscitations in British hospitals (the BRESSUS study): Methods and overall results. Br Med J. 1992;304:1347-51.

10. Ebell MH, Becker LA, Barry HC, Hagen M. Survival after inhospital cardiopulmonary resuscitation. A metaanalysis. J Gen Intern Med. 1998;13:805-16.

11. Dumot JA, Burval DJ, Sprung J, Waters JH, Mraovic B, Karafa MT, et al. Outcome of adult cardiopulmonary resuscitations at a tertiary referral center including results of «limited» resuscitations. Arch Intern Med. 2001;161:1751-8.

12. Schneider AP, Nelson DJ, Brown DD. In hospital cardiopulmonary resuscitation: A 30 year review. J Am Board Farm Pract. 1993;6:91-101.

13. Sandroni C, Nolan J, Cavallaro F, Antonelli M. In-hospital cardiac-arrest: Incidence, prognosis and possible measures for improve survival. Intensive Care Med. 2007;33:237-45.

14. Heart Disease and Stroke Statics-2009 Update. A report from the American heart Association Statics Comite and Stroke Statics Subcommittee. Circulation. 2009;119:e21-e181.

15. Cummins RO, Ornato JP, Thies WN, Pepe P. Improving survival from sudden cardiac arrest: The «chain of survival» concept: A statement for Health professionals from the Advanced Cardiac Life Support Subcomittee and the Emergency Cardiac Care Committee American Hearth Association. Circulation. 1991;83:1832-47.

16. Perales Rodríguez de Viguri N, Renes Carreño E, Fernández Álvaro P, Corres Peiretti MA. Sistemas integrales de emergencias: aspectos generales. En: Perales Rodríguez de Viguri N, editor. Avances en emergencias y resucitación. Barcelona: EdikaMed; 1996.

17. Perkins GD, Soar J. In hospital cardiac arrest: Missing links in the chain of survival. Resuscitation. 2005;66:253-5.

18. López Messa J. El paro cardíaco intrahospitalario: más allá del retraso en la desfibrilación. REMI. 2009;8. Disponible en: http://remi.uninet.edu/2008/01/REMIED63.html

19. Herrera Carranza M, López Camacho F. Plan hospitalario de reanimación cardiopulmonar y soporte vital. Servicio Andaluz de Salud. Consejería de Salud. Huelva: Hospital "Juan Ramón Jiménez"; 2007. Disponible en: http://www.semicyuc.org/ sites/default/files/Plan\%20HJRJ\%20RCP.pdf

20. Commins RO, Chamberlain D, Hazinski MF, Nadkarni V, Kloeck W, Kramer E, et al. Recommended guidelines for reviewing, reporting and conducting research on in-hospital resuscitation: The in-hospital «Utstein style». A statement for healthcare professionals form the American Heart Association, the European Resuscitation Council, the Heart and Stroke Foundation of Canada, the Australian Resuscitation Council, and the Resuscitation Council of Southern African. Resuscitation. 1997;34:151-83.

21. Jacobs I, Nadkarni V, Bahr J, Berg RA, Billi JE, Bossaert L, et al. Cardiac arrest and cardiopulmonary resuscitation outcome reports: Update and simplification of the Utstein templates for resuscitation registries. A statement for healthcare professionals from a task force of the international liaison committee on resuscitation (American Heart Association, European Resuscitation Council, Australian Resuscitation Council, New Zealand Resuscitation Council, Heart and Stroke Foundation of Canada, InterAmerican Heart Foundation, Resuscitation Council of Southern Africa). Resuscitation. 2004;63:233-49.

22. Brain Resuscitación Clinical Trial I Study Group. A randomized clinical study of cardiopulmonary cerebral resuscitation: Design, method and patient caractheristics. Am J Emerg Med. 1986; 4: 72-6.

23. Heart Disease and Stroke Statics-2009 Update. A report from the American Heart Association Statics Comite and Stroke Statics Subcommittee. Circulation. 2009; 117: e25-e146.

24. Fontanals J, Miró O, Pastor X, Grau JM, Torres A, Zavala E, et al. Reanimación cardiopulmonar en enfermos hospitalizados en unidades convencionales. Estudio prospectivo de 356 casos consecutivos. Med Clin (Barc). 1997;108:441-5.

25. Colmenero Ruiz M, De la Chica Ruiz-Ruano R, Chaveros Magro MJ, Pérez Villares JM, Reina Toral A, Rodríguez Elvira $M$. Resultados de la atención a la parada cardiorrespiratoria en un hospital de referencia según el estilo Utstein. Med Intensiva. 2004;28:49-56.

26. Frediksson $M$, Solveig $A$, Thorén AB, Herlitz J. In-hospital cardiac arrest. An Utstein style report of seven years experience from the Sahlgrenska University Hospital. Resuscitation. 2006;68:351-8.

27. Nadkarni VM, Larkin GL, Peberdy MA, Carey SM, Kaye W, Manicini ME, et al. First documented rhytm and clinical outcome from in-hospital cardiac arrest among children and adults. JAMA. 2006;295:50-7.

28. Sandroni C, Cavallaro F, Ferro G, Fenici P, Santangelo S. A survey of the in-hospital response to cardiac arrest on general wards in the hospitals of Rome. Resuscitation. 2003;56:41-7.

29. Pembeci K, Yildrim A, Turan S, Buget M, Camci E, Senturk M, et al. Assessment of the success of cardiopulmonary resuscitation attemps performed in a Turkish university hospital. Resuscitation. 2006;68:221-9.

30. Enoumah KO, Moerer O, Kirmse C, Bahr J, Neumann P, Quintel $M$. Outcome in cardiopulmonary resuscitation in intensive care units in a university hospital. Resuscitation. 2006;71:161-70.

31. Kaysera RG, Ornato JP, Peberdy MA. for the American Heart Association National Registry of Cardiopulmonary Resuscitation: Cardiac arrest in the Emergency Department: A report from the National Registry of Cardiopulmonary Resuscitation. Resuscitation. 2008;78:151-60.

32. López Messa JB. Incidencia y supervivencia del paro cardíaco. [artículo especial n. ${ }^{0}$ A102]. REMI. 2009;9. Disponible en: http://remi.uninet.edu/2009/05/REMIA102i.html

33. Perales Rodríguez de Viguri N, Alvarez Fernández J, López Messa JB. Introducción y conceptos básicos en resucitación cardiopulmonar. En: Perales Rodríguez de Viguri N, López Messa JB, Ruano Marco M, editores. Manual de soporte vital avanzado. 4. ${ }^{\mathrm{a}}$ ed. Barcelona: Elsevier Masson; 2007. p. 14-5.

34. Iwami T, Nichol G, Hiraide A, Hayashi Y, Nishiuchi T, Kajino K, et al. Continuous improvement in "Chain of Survival". Increased survival after out-of-hospital cardiac arrests. A large-scale population-based study. Circulation. 2009;119:728-34.

35. Galdós Asuncibay P. La Medicina Intensiva fuera de la $\mathrm{UCI}$ (outreach services). En: Roca Guiseris J, Ruíz Moreno J, editores. Barcelona: Edika; 2005. p. 221-36.

36. Gazmuri RJ, Álvarez-Fernández JA. Tendencias en resucitación cardiopulmonar. Med Intensiva. 2009;33:31-9.

37. Scales DC, Abrhamson S, Brunet F. The ICU outreach team. J Crit Care. 2003;18:95-106.

38. Jones D, Bellomo R, Bates S, Warrillow R, Goldsmith D, Hart G, et al. Long term effect of a medical emergency medical on 
cardiac arrests in a teaching hospital. Critical Care. 2005;9: R808-R815.

39. Chan PS, Khalid A, Longmore LS, Berg RA, Kosiborod M, Spertus JA. Hospital-wide code rates and mortality before and after implementation of a rapid response team. JAMA. 2008;300: 2506-13.

40. Cuthbertson BH. Optimising early warning scoring systems. Resuscitation. 2008;77:153-4.

41. Kellett J, Deane B, Gleeson M. Derivation and validation of a score based on Hypotension, Oxygen saturation, low Temperature, ECG changes and Loss of independence (HOTEL) that predicts early mortality between $15 \mathrm{~min}$ and $24 \mathrm{~h}$ after admission to an acute medical unit. Resuscitation. 2008;78:52-8.

42. Ehlenbach WJ, Barnato AE, Curtis JR, Kreuter W, Koepsell TD, Deyo RA, et al. Epidemiologyc study of in-hospital cardiopulmonary resuscitation in the elderly. N Engl J Med. 2009;361: 22-31.

43. Peberdy MA, Ornato JP, Larkin GL, Braithwaite RS, Kashner TM, Carey SM, et al. Survival from in-hospital cardiac arrest during nights and weekends. JAMA. 2008;299:785-92.

44. Wright NM, Stenhouse CW, Morgan RJ. Early detection of patients at risk (PART). Anaesthesia. 2000;55:391-2.

45. Goldhill DR, McNarry AF. Physiological abnormalities in early warning scores are related to mortality in adult patients. $\mathrm{Br} \mathrm{J}$ Anaesth. 2004;92:882-4.
46. Hanefeld C, Lichte C, Mentges-SchröterSirtl C, Mügge A. Hospital-wide first-responder automated external defibrillator programme: 1 year experience. Resuscitation. 2005;66:167-70.

47. Chan PS, Krumholz HM, Nichol G, Nallamothu BK, American Heart Association National Registry of Cardiopulmonary Resuscitation Investigators. Delayed time to defibrilation after inhospital cardiac arrest. N Engl J Med. 2008;358:9-17.

48. Herlitz J, Bang A, Alsen B, Aune S. Characteristics and outcome among patients sffering from in-hospital cardiac arrest in relation to wheter the arrest took place during office hours. Resuscitation. 2002;53:127-33.

49. Brindley PG, Markland DM, Mayers I, Kutsogiannis DJ. Predictors of survival following in-hospital adult cardiopulmonary resuscitation. CMAJ. 2002;167:343-8.

50. Chan PS, Nichol G, Krumholz HM, Spertus JA, Nallamothu BK. Hospital variation in time to defibrillation after in-hospital cardiac arrest. Arch Intern Med. 2009;169:1265-73.

51. Nichol G, Thomas E, Callaway CW, Hedges J, Powell JL, Aufderheide TP, et al. Regional variation in out-of hospital cardiac arrest incidence and outcome. JAMA. 2008;300: 1423-31.

52. Carr BG, Goyal M, Band RA, Gaiesky DF, Abella BS, Merchant RM, et al. A national analysis of the relationship between hospital factors and post-cardiac arrest mortality. Intensive Care Med. 2009;35:505-11. 